\title{
Monetary Stabilization Policy: Evidence from Money Demand Forecasts
}

\author{
R. W. Hafer
}

$\mathbb{E}$ key ingredient in the formulation of monetary policy. Recently, some analysts have argued that financial innovations have rendered the money dernand relationship unstable. Because of this, intermediate monetary targeting - a policy that is based on the predictability of money demand - has been viewed as a dubious policy procedure to follow.'

In this article, we investigate the stability of two commony estimated money demand functions. Specifically, we examine whether there has been a statistically significant change in the estimated relationships between those found for the period $1960-79$ and those for the period 1960-84.

We also examine the forecasting ability of the two models. "To do this, the equations are estimated over the 1960-79 sample and are used to generate quarterly forecasts for the $1980-84$ period. By observing the forecast errors in conjunction with the stability test results, we can better assess the validity of the recent arguments against monetary targeting.

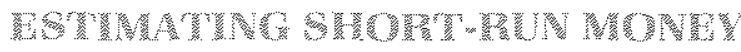

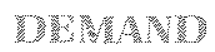

An extensive literature exists on the appropriate

R. W. Hafer is a research officer at the Federal Reserve Bank of St. Louis. Larry J. Dimariano provided research assistance.

'For example, Higgins and Faust (1981), p. 17, note that financial innovations create an atmosphere in which "it may be necessary to reevaluate the desirability of using monetary targets to achieve ultimate policy objectives." In this vein, Davis (1981), p. 24, sug. gests that "perhaps more subtle and pervasive questions about the desirability of pursuing rigorously monetary growth targets are raised by questions about the stabifity of the 'demand for money'." form of the short-run money demand function." To investigate the issue of money demand stability, we have chosen two common specifications. These are (1) $\ln (\mathrm{M} / \mathrm{P})_{1}=\alpha_{4}+\alpha_{1} \ln y_{4}+\alpha_{2} \ln \mathbf{R}_{1}+\alpha_{3} \ln (\mathbf{M} / \mathbf{P})_{\mathrm{k-1}}+\varepsilon_{\mathrm{i}}$, and (2) $\ln (\mathrm{M} / \mathrm{P})_{1}=\alpha_{\mathrm{a}}^{\prime}+\alpha_{1}^{\prime} \ln y_{4}+\alpha_{z}^{\prime} \ln \mathbf{R}_{4}+\alpha_{3}^{\prime} \ln \left(\mathrm{M}_{t, r} / P_{1}\right)+\varepsilon_{1}^{\prime}$, where $\mathrm{M}=$ nominal $\mathrm{M1}$,

$$
\begin{aligned}
\mathbf{P}= & \text { the price level measured by the GNP } \\
& \text { deflator }(1972=100), \\
y= & \text { a scale variable represented by real GNP } \\
& (\$ 1972), \\
R= & \text { a nominal market rate of interest, mea- } \\
& \text { sured by the commercial paper rate, ard } \\
\varepsilon= & \text { a random error term. }
\end{aligned}
$$

Equations 1 and 2 are the so-called real and nominal adjustment specifications, respectively. These two equations differ in that the real adjustment specificathon assumes that individuals adjust their actual real money balances to their desined level. The nominal adjustment specification, on the other hand, assumes that individuals adjust their nominal money balances to their desired level. Although the two equations appeaf equivalent except for the adjustment variable, the dependent variable in equation 2 actually is the logarithm of nominal money. Because there is no consensus on which of these two specifications is correct, both are used.

\footnotetext{
2For a survey of the literature, see Laidier (1977),

Thornton (1985) discusses this point and provides a more complete discussion of the derivation of the two money demand specifications.
} 


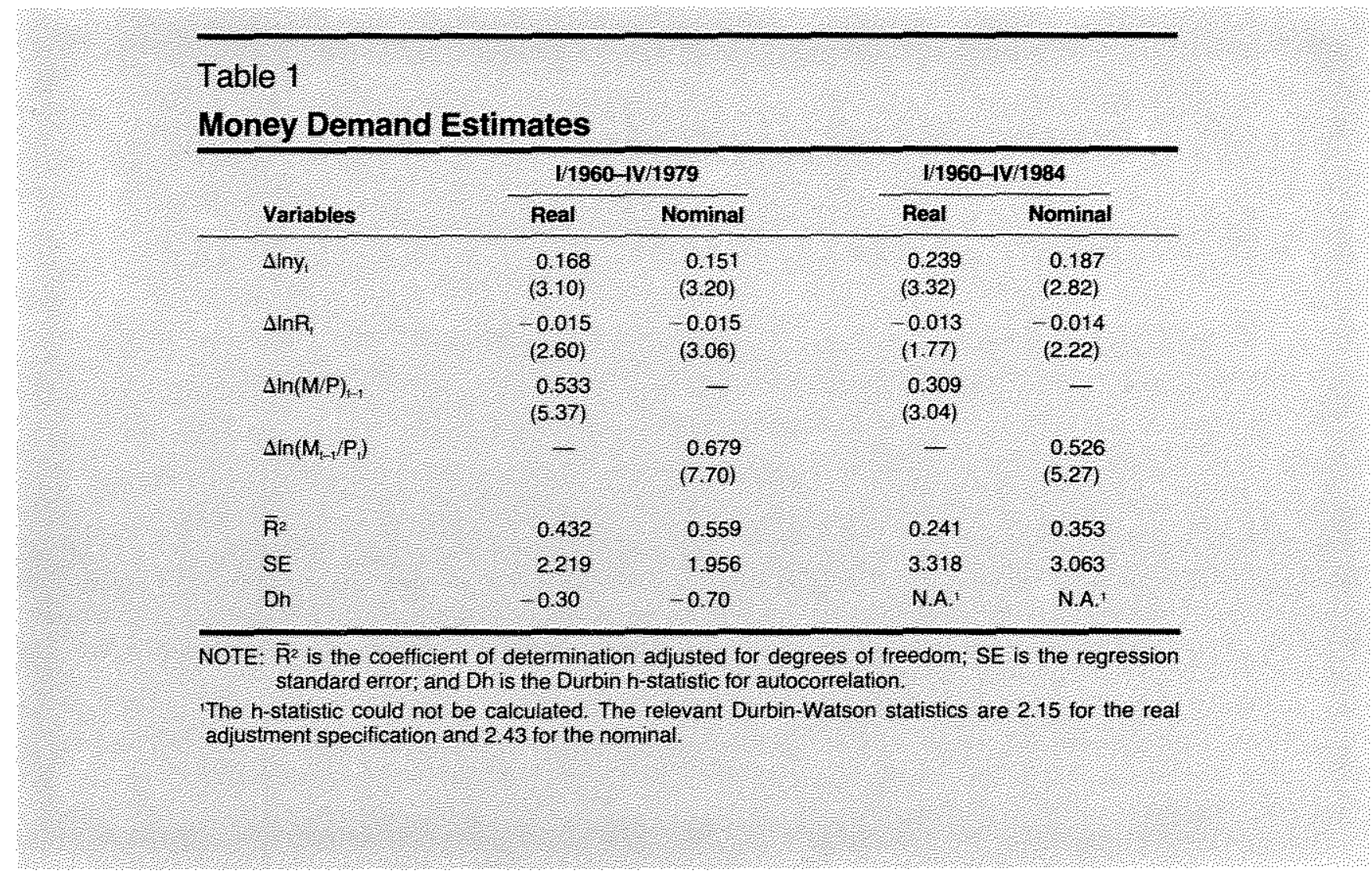

A number of studies have found that the estimated coefficients in equations 1 and 2 are statistically unstable when estimated across the mid-1970s. This instability has been ascribed to a variety of causes, including large changes in the price level, a wealth loss due to OPEC oil shocks, changes in financial management techniques and more. ${ }^{+}$It has been shown, however, that this instability of the level version is reduced greatly when the equation is estimated in first-difference form, at least up to $1980 .^{5}$ The general use of differencing has been suggested by Granger and Newbold (1974) and Plosser and Schwert (1978) to achieve stationarity and to reduce the possibility of a spurious regression result. On this point, a recent study by Layson and Seaks (1984) presents evidence indicating that the first-difference version of the money demand specification is statistically preferable to its level form.

Based on these findings, therefore, we use the firstdifference versions of equations 1 and 2 in this study. Thus, the equations estimated and analyzed in this article are:

${ }^{4}$ A survey of the relevant literature is presented in Judd and Scadding (1982) and Roley (1985)

5This finding initially was reported in Hafer and Hein (1982)
(3) $\Delta \ln \left(\mathrm{M} / \mathrm{P}_{1}=\beta_{1} \Delta \ln y_{1}+\beta_{2} \Delta \ln \mathrm{R}_{\mathrm{f}}+\beta_{3} \Delta \ln \left(\mathrm{M} / \mathrm{P}_{3-1}+\phi\right.\right.$

(4) $\Delta \ln (\mathrm{M} / \mathrm{P})_{1}=\beta_{1}^{\prime} \Delta \ln \mathrm{y}_{\mathrm{t}}+\beta_{2}^{\prime} \Delta \ln \mathrm{R}_{1}+\beta_{3}^{\prime} \Delta \ln \left(\mathrm{M}_{\mathrm{l}, \mathrm{s}} / \mathrm{P}_{\mathrm{k}}\right)+\phi_{1}^{\prime}{ }^{\mathrm{s}}$

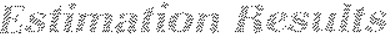

Equations 3 and 4 are estimated for two sample periods: I/1960-IV/1979 and I/1960-IV/1984. The split at 1980 is used to determine the stability of the model during the past five years, a period of substantial financial market change. The question addressed is whether the results from the earlier period are statistically different from those of the latter.

The results of estimating equations 3 and 4 are presented in table 1. Looking at the 1960-79 results, the estimated short-run income and interest rate elasticities are similar across specifications. The estimated coefficient on lagged money balances in equation 3 is

ENote that the constant term does not appear in the first-difference equations. This is due to the algebraic manipulation of the level equation to generate the first-difference model. it shoutd be noted, however that incorporating a constant term into the first-difference equation represents a time trend variable from the level equation. Estimating the first-difference equations with the constant term found it to be insignificantily different from zero.

The estimation properties of the (real) equation for the $1960-79$ period are presented in Hafer and Hein (1982). 


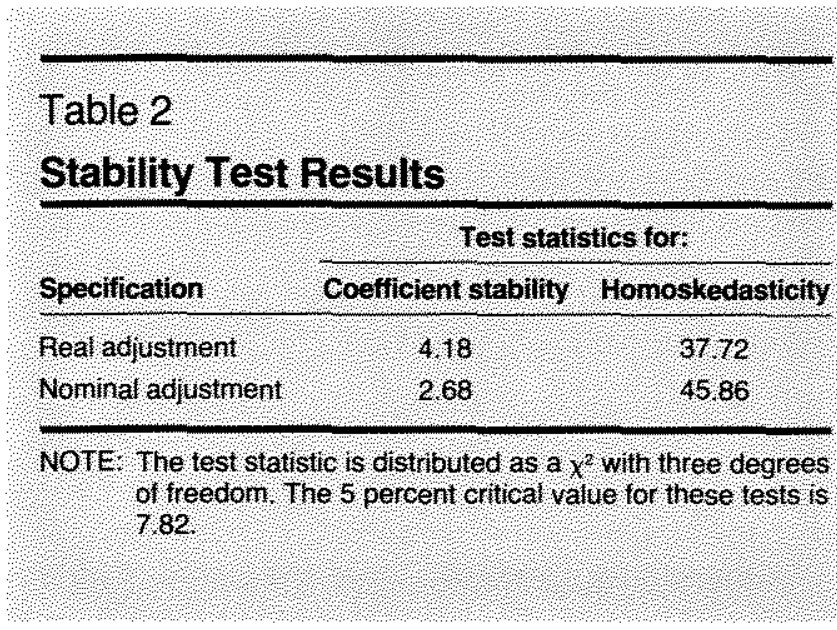

0.533, implying an adjustment speed of 47 percent per quarter, For the nominal adjustment model, the estimated coefficient is 0.679 , which yields an adjustment coefficient of 32 percent per quarter.

The differences in the estimated adjustment speeds produce different long-run income and interest rate elasticities. The long-run income elasticity from the real specification is 0.36 ; from the nominal model it is 0.47. Each estimate is slightly less than values reported in previous studies." The differences are especially noticeable in the long-run interest elasticities: the longrun interest elasticity from the real model is -0.032 , while that from the nominal model is -0.047

When the equations are estimated for the full 1960 84 period, some notable changes occur in the coefficient estimates. In each equation, the estimated short-run income elasticity increases in value, while the estimated coefficient on the lag term declines. Interestingly, the estimated short-run interest elasticities are little changed by the increased sample data

\section{A}

Comparing the two equations across the two sample periods indicates a substantial increase in the regression standard error. This increase suggests that the equations may not be statistically stable; that is, the estimated statistical relationship may have changed significantly across the sample.

'To examine this issue, each equation was tested for stability of the estimated coefficients and for stability of the emor structure. This dichotomy is important,

${ }^{8}$ For a critical interpretation of such results, see Goodfriend (1985). FFor a comparison with previous results, see Judd and Scadding (1982). because tests for coefficient stability in the presence of

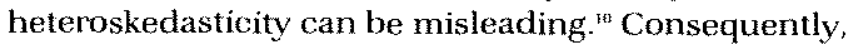
two test statistics are reported for each specification. One tests for coefficient stability, allowing the variance to change; the other tests for constant variance, with the coefficients allowed to change. The relevant test statistics are reported in table 2 .

The results for each specification indicate that we cannot reject the hypothesis that the estimated coefficients are statistically constant across the 1979 break. Each of the calculated chi-squared statistics is well below the 5 percent critical value. The results of test ing for homoskedastic errors indicates, however, that we can easily reject the hypothesis of constant variance over the two periods. This outcome suggests that the exogenous influences affecting the error term have changed between the two petiods.

The stability evidence indicates that, contrary to some recent findings, the estimated coefficients of the real and nominal adjustment models of money demand have not changed significantly during the past five years when compared with those from the 1960 79 sample." The question to which we now turn is, why has the variance of the estimate relationships changed? To do this, we examine the models' forecast errors for the post-1979 period.

\footnotetext{
"See Thornton for a related discussion on this point and the likelihood ratio tests used here.

"Thomton recently has reported that there is some evidence of instability for the real and nominal adjustment models. it should be noted, however, that his tests are based on the level specification. Also, his estimated equations include the passbook savings rate as an additional explanatory variable. Even with these differences, however, his parameter stability test results for the nominal adjustment model without the passbook rate estimated over the $1962-84$ period indicate that stability cannot be rejected at the 5 percent level of significance.
}

Gordon (1984), on the other hand, reports the firsi-difference model to be unstable, based on a simple F-test. The reported test results examine the overall fit of the model. It is possible to test the stability of each coefficient over the 1979 break through the use of dummy variables. Let D1 $=1$ for $1 / 1960-I V / 1979$ and zero elsewhere, and D2 1 for I/1980 - V/1984 and zero elsewhere. Forming interaction terms with the right-hand-side variables, we may test the difference between coefficients estimated for each subsample. Testing the null hypothesis of coefficient equality, the absolute value of the calculated twstatistics for the real adjustment model variables are: income -1.50 ; commercial paper rate -0.14 ; and lagged term -2.22 . The $t$-statistics from the nomiral adjustment model are: income -0.92 ; commercial paper rate -0.02 ; and lagged term -1.68 .

This evidence suggests that the lagged tem in the real-adjustment model has changed. In contrast, none of the coefficients in the nominal adjustment model have changed, providing some basis for the preference of this version. It should be noted, however, that this test procedure does not account for changes in the error variance. 


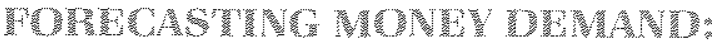

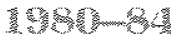

A computationally convenient procedure to examine the post-1979 forecast results for each specification is suggested by Dufoup $(1980,1982)$. This tech nique uses separate $(0,1)$ dummy variables entered for each individual observation beyond a selected break point. In the present example, a dummy variable D1 was entered as 1.0 for $1 / 1980$ and zero elsewhere; D2 was entered as 1.0 for II/1980 and zero elsewhere; and so on through $I V / 1984$. When added to equations 3 and 4 and estimated over the full 1960-84 sample period, the estimated coefficients on the dummy variables represent post-sample static forecast errors. Moreover, the t-statistic for each dummy variable provides information about which forecast error significantly departs from the 1960-79 regression model. Thus, by examining the estimated coefficients on the dummy variables for the $1 / 1980-I V / 1984$ period, we can determine the magnitude of the forecast error and determine the sign pattem of the errors."

On this last point, we especially are interested in whether there are transitory errors - errors that alternate in sign - or whether the errors are generally onesided. Significant transitory errors suggest that the model is subject to random shocks that are larger during the forecast period than the average squared error experienced during the estimation sample. A forecast error pattern that has consistently significant, one-sided errors, however, suggests that the relationship embodied in the estimated model has changed from that in the estimation period.

To statistically investigate the nature of the forecast errors, it is informative to test whether the sum value of the forecast errors is statistically different from zero. If this hypothesis is rejected, the evidence would indicate that the forecast errors are offsetting in sign and magnitude.

The estimated dummy variable coefficients and tstatistics for both the real and nominal adjustment models are reported in table $3{ }^{13}$ The evidence for the real adjustment model indicates that there have been

\footnotetext{
12 This procedure also is used by Hafer (1985) to investigate the stability of money demand during the 1920-39 period.

${ }^{13}$ The estimated coefficients on the other variables are not reported since, by construction of the test, they are identical to the 1960-79 estimates found in table 1 .
}

several statistically significant departures from the regression model during the past five years. The first two are in $1 / 1980$ and $11 / 1980$, when special credit controls were initiated by the Carter administration. These errors are by far the largest; more important, however, is the fact that they are offsetting in sign and magnitude. This result is consistent with the notion that the credit control program had only a temporary effect on the money demand forecast errors."

The remaining significant forecast errors are found mostly in 1981 and 1982. The errors in 1981 occur during the first three quarters, a period associated with the nationwide legalization of NOW accounts. More important is the result that the errors alternate in sign and are of approximately equal magnitudes. This also holds true for the errors found in the first two quarters of 1982. The forecast errors found in 1981 and 1982 corroborate previous findings about the increased variability of velocity growth during this period. The evidence here suggests that these errors were transitory. ${ }^{\text {s. }}$

The forecast errors from the nominal adjustment specification follow a pattern similar to those from the real adjustment model. The sign pattern generally holds between the two error series, and the significant errors are located in the same periods, except for II/ 1983. In that quarter, the nominal adjustment model's forecast error $(2.357)$, unlike that of the real adjustment model, is not statistically significant at the 5 percent level.

The F-statistic reported below each forecast series tests the hypothesis that the sum of the forecast errors is zero. The reported F-statistics are quite low and, as indicated by the significance levels reported in parentheses, do not permit rejection of the null hypothesis at any reasonable level of significance. Thus, finding that the sum of the money demand forecast errors from the real and nominal adjustment specifications are not different from zero corroborates the previous

${ }^{14}$ For relevant discussions of this finding, see Judd and Scadding (1981) and Hein (1982). Indeed, our evidence suggests that large fuctuations in the nominal money stock, such as those associated with the credit control period, may explain observed errors in the money demand model. Such a theory is suggested by Carr and Darby (1981).

${ }^{15}$ See Tatom (1983), Judd and Motey (1984), Hater (1984a, b) and Gordon (1984) for discussions of this period. Interestingly, the signs of the forecast errors during this period do not conform with those predicted by some financial innovation arguments.

For a discussion of how financial innovations have influenced money demand estimates in Japan, see Suzuki (1984). 
Table 3

Estimates of Post-1979 Forecast Errors

\begin{tabular}{|c|c|c|c|c|}
\hline \multirow[b]{2}{*}{ Variables } & \multicolumn{2}{|c|}{ neal } & \multicolumn{2}{|c|}{ Nominal } \\
\hline & Estimates & Istatistic & Estimates & trstatistic \\
\hline 11980 & $-1,532$ & 0.68 & 0.357 & 0.18 \\
\hline 4 ४ & 712.344 & 531 & $(14211$ & 5.49 \\
\hline 111 & 136613 & 4.25 & 14358 & 6.48 \\
\hline ve & 41520 & 0.62 & 40.923 & 0.43 \\
\hline 11081 & 8.922 & 3,92 & 8.991 & 4449 \\
\hline 1 & 6.657 & 4284 & 4,924 & 248 \\
\hline 111 & 48013 & ?360 & 40098 & -3.6 \\
\hline U & 0.055 & 0.02 & 40.05 & -0.09 \\
\hline $1 / 1982$ & $\% 6008$ & 307 & 489 & $2,48 \%$ \\
\hline I & 44678 & 207 & 4.684 & -236 \\
\hline 111 & 2915 & 1,29 & 4,857 & 0.93 \\
\hline 10 & 9689 & 4416 & 9.251 & 451 \\
\hline $1 / 1983$ & 4,358 & 0.53 & 2.072 & 0095 \\
\hline ४ı & 44696 & 42.04 & 2,357 & $\checkmark 1,14$ \\
\hline 11 & 4,482 & 40.63 & 0,558 & 4027 \\
\hline VI & 2.883 & 4.1 .24 & 29983 & 1448 \\
\hline 411984 & 0.617 & 0.27 & 0.704 & 0.36 \\
\hline 11 (t) & 4,75 & 0.78 & 0.908 & 40.46 \\
\hline 111 & 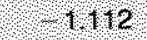 & 0.50 & 4.137 & 0.58 \\
\hline IV & .7 .658 & 073 & 2487 & ? 123 \\
\hline $\mathrm{P}$ & $\begin{array}{l}0.094 \\
(0.76)\end{array}$ & & $\begin{array}{l}0.048 \\
(0.83)\end{array}$ & \\
\hline
\end{tabular}

Derotes signilicance at 5 percent level.

result of stable coefficient estimates."

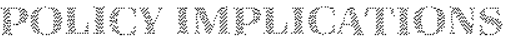

The empirical evidence suggests that the relationship between the growth of money balances and its economic determinants is more stable than some have argued. Although there is evidence of large post-

16In detemining the significance of the individual dummy variables, it should be noted that they are being compared with the regression model estimated through IV/1979. in this way, the large forecast errors do not influence the two-standard-error interval used to locate the significant forecast errors.

If may be argued that the evidence on the sum of the forecast errors holds only over the long period forecasted and that the use of selected subperiods would show the average error not to be zero. This argument misses the point: because there always are shortterm folecast errors, some of which can be "large," policies that attempt to exploit such quarterly deviations from forecasts may fail to achieve desired longer term monetary policy goals. Because the longer-term resulis indicate that the errors average to zero over time, a longer-view policy may better achieve desired longer-term goals, such as price stability and income growth.
1979 forecast егтог, these errors are transitory and the sum of the forecast errors is not statistically different from zero. This evidence suggests that monetary policies relying on quarter-to quarter forecasts of money demand growth may not fare well because of the random, unpredictable component inherent in the estimated relationship. It also suggests, however, that the secular relationships embodied in the money demand function may be exploited successfully by emphasizing long-tw money growth and GNP growth objectives."

\footnotetext{
17This conclusion also is reached by Hein and Veugelers (1983) in their study of velocity. In that article, the predictability of the quarterto-quarter growth of M1 velocity was examined. Their evidence indicated that, on a quarterly basis, velocity growth fluctuated randomly about a fixed mean. As the forecast horizon was extended, the accuracy of the forecasts improved. Thus, in the context of a simple quantity theory model, given some desired growth for nominat income, determining the correct growth for money based on a forecast of velocity (or money demand) will be successful only for horizons longer than one or two quarters.
} 


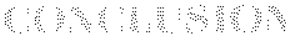

In this article, we have presented evidence indicating that the estimated coefficients from two common short-run money demand specifications are statistically stable across the 1960-84 period. Using IV/1979 as the hypothesized break point, we could not reject the hypothesis of stable coefficients. We also presented evidence showing that the estimated residuals have not remained constant over this time period. Further testing indicated that the reason for this heteroskedasticity stems from the large errors experienced by each equation primarily during the turbulent 1980-82 period.

Although the evidence reveals large quarterly forecast errors during the past five years, the results also show that these errors are offsetting in sign and magnitude. In fact, the sum of the forecast errors from each model is not statistically different from zero. This result substantiates previous findings from studies of velocity growth in which the forecast accuracy improved as the forecast horizon was lengthened. In this vein, arguments that monetary targeting to achieve the long-term goals of stable income growth and price stability has become useless because of purported money demand instability are not supported by the evidence.

\section{BA?}

Carr, Jack, and Michael R. Darby. "The Role of Money Supply Shocks in the Short-Run Demand for Money," Joumal of Monetary Economics (September 1981), pp. 183-99.

Davis, Richard. "Monetary Aggregates and the Use of 'Intermediate Targets' in Monetary Policy, "in New Monetary Control Procedures, Vol. I. Board of Governors of the Federal Reserve System (February 1981)

Dufour, Jean-Marie. "Dummy Variables and Predictive Tests for Structural Change," Economics Letters (3: 1980), pp. 241-47.

"Predictive Tests for Structural Change and the St. Lous Equation" (University of Montreal, processed, 1982).

Goodfriend, Marvin. "Reinterpreting Money Demand Regressions," in Karl Brunner and Allan H. Meltzer, eds., Understanding Monetary Regimes, Cannegie-Rochester Conference Series on Public Policy (North-Holland, Spring 1985), pp. $207-42$.
Gordon, Robert J. "The Short-Run Demand for Money: A Reconsideration," Journal of Money, Credit and Banking (November 1984), pp. $403-34$

Granger, Clive W. J., and Paul Newbold. "Spurious Regressions in Econometrics," Journal of Econometrics (July 1974), pp. 111-20.

Hater, A. W. "The Money-GNP Link: Assessing Alternative Transaction Measures," this Review (March 1984a), pp. 19-27.

"Money, Debt and Economic Activity," this Review (June/July 1984b), pp. 18-25.

"The Stability of the Short-Run Money Demand Funcion, 1920 1939," Explorations in Economic History (forthcoming. July 1985).

Hafer, R. W., and Scott E. Hein. "The Shift in Money Demand: What Really Happened?" this Review (February 1982), pp. 11-16.

Hein, Scott E. "Short-Run Money Growth Volatility: Evidence of Misbehaving Money Demand?" this Review (June/July 1982), pp. $27-36$.

Hein, Scott E., and Paul T. W. M. Veugelers. "Predicting Velocity Growth: A Time Series Perspective," this Review (October 1983). pp. 34-43.

Higgins, Bryon, and Jon Faust. "Velocity Behavior of the New Monetary Aggregates," Federal Reserve Bank of Kansas City Eco. nomic Review (September/October 1981), pp. 3-17.

Judd, John P., and John L. Scadding. "Liability Management, Bank Loans, and Deposit 'Market' Disequilibrium," Federal Reserve Bank of San Francisco Economic Revew (Summer 1981), pp. 2144.

"The Search for a Stable Money Demand Function: A Survey of the Post-1973 Literature," Journal of Economic Literature (September 1982), pp. 993-1023.

Judd, John P., and Brian Motley. "The 'Great Velocity Decine' of 1982-83: A Comparative Analysis of M1 and M2," Federal Reserve Bank of San Francisco Economic Review (Summer 1984), pp. 56-74.

Laidler, David E. W. The Demand for Money: Theories and Evidence (Oun-Donnelley, 1977).

Layson, Stephen K., and Terry G. Seaks. "Estimation and Testing for Functional Form in First Difference Models," Review of Economics and Statistics (May 1984), pp. 338 43.

Plosser, Charles I., and G. Willam Schwert. "Money, Income and Sunspots: Measuring Economic Relationships and the Effects of Differencing," Journal of Monetary Economics (November 1978), pp. 637-60.

Roley, V. Vance. "Money Demand Predictability," paper presented at American Enterprise institute Conference on Monetary Policy in a Changing Financial Environment, February 8, 1985.

Suzaki, Yoshiu, "Financial Innovation and Monetary Policy in Japan," Bank of Japan Monetary and Economic Studies (June 1984), pp. 1-47.

Tatom, John A. "Was the 1982 Velocity Decline Unusual?" this Review (August/September 1983), pp. 5-15.

Thomton, Daniel L. "Money Demand Dynamics: Some New Evidence," this Review (March 1985). 